\title{
Peter OLEN, Wilfrid Sellars and the Foundations of
}

Normativity

London, Palgrave Macmillan, 2016, 240 pages

\section{Gabriele Aleandri}

\section{OpenEdition}

Journals

Electronic version

URL: http://journals.openedition.org/ejpap/1180

DOI: 10.4000/ejpap. 1180

ISSN: 2036-4091

Publisher

Associazione Pragma

\section{Electronic reference}

Gabriele Aleandri, "Peter oLEn, Wilfrid Sellars and the Foundations of Normativity », European Journal of Pragmatism and American Philosophy [Online], X-1 | 2018, Online since 20 July 2018, connection on 24 September 2020. URL : http://journals.openedition.org/ejpap/1180 ; DOI : https://doi.org/10.4000/ ejpap. 1180

This text was automatically generated on 24 September 2020

\section{(c) $\odot \Theta \Theta$}

Author retains copyright and grants the European Journal of Pragmatism and American Philosophy right of first publication with the work simultaneously licensed under a Creative Commons AttributionNonCommercial-NoDerivatives 4.0 International License. 


\title{
Peter OLEN, Wilfrid Sellars and the Foundations of Normativity
}

London, Palgrave Macmillan, 2016, 240 pages

\author{
Gabriele Aleandri
}

\section{REFERENCES}

Peter OLEN, Wilfrid Sellars and the Foundations of Normativity, London, Palgrave Macmillan, 2016, 240 pages

1 In many ways, the figure of Wilfrid Sellars personifies the second half of xxth century American philosophy. He lied at the crossroad of three powerful traditions: German rationalistic phenomenology, as Marvin Farber's scholar; logical empiricism, as a philosopher grown up in the golden age of neo-positivism; and classical pragmatism, as an intellectual deeply inspired by the need of keeping a synoptic vision and finding practical and behavioral solutions for conceptual oppositions. In his last book, Wilfrid Sellars and the Foundations of Normativity, Peter Olen makes these philosophical backgrounds emerge, together with a strong professional and intellectual link to the prominent minds of his time, throughout the formal and rigorous style of Sellars's works, lighting up the changes in his main philosophical concerns and in the solutions he gave them.

2 The book is divided into two parts. The first one offers, in Olen's words, "a historical account of Sellars's early thought that both situates his attempt to formalize pragmatics among his peers and historically grounds his conception of language and linguistic rules as it developed from his earliest, under-analyzed publications to his most cited works in the 1950s and 1960s" (p. 2); the second one is a precious appendix of unpublished manuscripts and epistolary concerning the development of Sellars's philosophy described in the first part. But the book ends up in being more than a work of philosophical historiography correcting the widespread ahistorical interpretation of Sellars; it is a historical reconstruction aimed to clarify and possibly solve some 
philosophical problems arisen from misunderstandings between Sellars and his interpreters, and even between Sellars and other important philosophers as Carnap, Feigl and C.I. Lewis. Since The Pittsburgh School, in its position between neopragmatism and neo-analytical philosophy, has become more and more influential through the years, such a clarification on his founder's thought is much more than a philological work.

The central topic of the book seems to be Sellars's shift from a formalist to a worlddirected conception of philosophy, its backgrounds and its reasons. Olen's point of view is that the needs contained in Sellars's first formalism - preserving the distinction between philosophy and the empirical sciences, and at the same time preserving a quasi-scientific method for philosophy itself - found an answer in his later psychosociological reconstruction of meaning, but this did not happen as part of a precise philosophical strategy. The reasons behind Sellars's first peculiar mix of rationalism and logical empiricism are essentially historical, depending on the unsatisfactory coherentist interpretation that had been given of Carnap's pure semantics at the University of Iowa. Sellars thought that pure pragmatics would have been a proper answer to such coherentism, but his refusal in giving his pragmatics a link to the real world (and not only to the logically possible ones) made impossible finding a clear formulation of the oxymoronic "pure pragmatics." Only when he started reading Carnap correctly he significantly changed his own philosophical aims, which in the end were satisfied by a new formulation of the "solutions" he gave to his earlier concerns and made the final picture of his philosophy as apparently fully original and selfdeveloped.

However, as the title of the book suggests, Olen's real point was to focus on the concept of normativity as the key to understanding how different paths in Sellars's philosophy have converged in a coherent conception. In his early formalism, Sellars shared the positivistic vision that admitted substantially two kinds of rules for language: logical ones, which make language understandable, and conformation ones, with Sellars's insistence in claiming, for the latter, something like an a priori deduction (in order to avoid both scientism and anti-naturalistic psychologism). The deep point of agreement with the positivists was Sellars's conviction that there is something as an "empirical meaningfulness" that makes us capable to distinguish between understandable and senseless sentences. The passage to his later philosophy is clearly marked by the dissolution of this notion by two paramount considerations: first, the admittance that empirical meaningfulness and conformation rely on the criteria of a community of speakers; second, the discover that modal expressions and moral commitment introduce in our language numberless sentences which are not reducible to an extensional or descriptive language, and can be considered "empirical" only in a broad sense. At the end, these considerations also better justify Sellars's early most unmotivated assumption: the conviction that philosophy can and have to maintain an explanatory role in the age of sciences, although being not in competition with them. And how did this change in his meta-philosophy influence his original conception of normativity? Olen wisely reformulates this question in a different way: "The most relevant question to ask, then, might not be 'Does Sellars's change in meta-philosophy cause him to abandon his earlier philosophical positions?', but 'How does Sellars' later meta-philosophy change the justification (or lack thereof) for his first-order position?" (100). 
5 The author suggests that the answer should be sought by taking a look at the exchanges between Carnap and Sellars himself. For Carnap and the early Sellars, formalism (and pure pragmatics) is a part of the scientific method that investigates language. For the later Sellars, instead, a non-factual characterization of language says something about the nature of the language, i.e. about meaning. This bold connection between the formal analysis and the concreteness of meaning is possible because of the broader conception of "empirical" mentioned above and, of course, because of Sellars's behavioristic inclination, which allowed him to sing the praises of the S-R principle all together with the arguments for the irreducibility of intentionality to descriptive language (in front of his floored colleagues and friends). And, if we look at these three different points behavior, intentional language and formal language - we can appreciate how normativity holds them together, since the latter is traditionally composed of formal principles independent from empirical order and concerning behavior. Finally, and in a perfectly coherent way, Olen makes two very different conceptions of language and normativity emerge: the first one, typical of Carnap, which substantially denies that normativity is sui generis and that there is continuity between the formal structure of language and its world-aboutness; and the second one, which is more or less the opposite and focuses on the hermeneutic link between logical generalizations and pragmatics.

6 Despite the fact that his reconstruction of Sellars's thought makes the last one seem precisely an attempt to mediate, through practical arguments, between formal requirements of meaning and its dependency on the world, Olen is very careful in finding Kantian elements or even a Kantian project behind it. Since this book has explicit goals of historical contextualization, it is quite clear that insisting in underlining the similarities between Sellars and a xvinth century's philosopher would look like an odd move. But the idea that in normative language we can find the connection between words and the world that we cannot find between conformation rules and natural laws has much more of the Kantian primacy of practical philosophy over theoretical than we can ignore, like also the division of philosophy from both scientific laws and contingent facts and the search for non-arbitrary rules in formation and transformation of sentences and connection of different meanings.

7 All the point is, of course, the sense of that "non-arbitrary," that could decide in which direction Sellars's Kantianism is oriented - if at all. Both the possibilities chosen by Sellars (in his formalist period, "non-arbitrary" in the sense of "logically independents from the world," later "non-arbitrary" as "constitutive of natural languages") are open to the same two-fold interpretation, which was magnificently expressed by Everett Hall in a letter to Sellars himself in 1947:

If one gives up realism in favor of linguistic formalism, one is landed not in Berkeleyan idealism but in absolute idealism. I think it also to be commended for showing that the coherence theory is not only of truth, but also of verification, that is its 'coherence' (in your terminology, 'rules of conformation') is neither logical consistency nor a merely contingent set of P-laws, but something peculiar in between and, that its plausible outcome is not absolutism but relativism, that is, both 'true' and 'verified' are relative to some "story." (182)

8 Even when Sellars abandoned formalism, the idea that "both 'true' and 'verified' are relative to some story" remained unmatched in its crucial position, in the form of the dependence of conformation rules from psycho-sociological facts. As Hall pointed out, with a bit of prophetic talent, such a dependence might mean two different things: if 
there is only one "story," one is landed very near to a naturalized version of absolute idealism; if there are many, one is landed in to the open relativism that Kant leaves behind after his transcendental machinery is abandoned. And this choice was going to be the central philosophical question for The Pittsburgh School, with - more or less John McDowell on one side and Robert Brandom on the other. McDowell, from Mind and World, has found a way to keep together world-aboutness and coherence insisting in saying that the world exercises conceptual force on a animals receptive to meaning; in Hall's words, "true" and "verified" are both relative to a story and to the world, since the world somehow tells the same story to all rational beings. In doing this, McDowell is giving complete development to the Hegelian aims in Sellars's philosophy, maybe to the detriment of his original insistence on the independence of the space of reason from the space of nature, famously claimed in the sentence that knowledge is entirely and only collocated in the first one. This development is subtly ironical, since McDowell's professed quietism starts just after he has reopened the main door for metaphysics, which is the Parmenidean identity of structure between thought and world. Brandom, on the other hand, interprets Sellars's story-dependency of truth and verification as an admittance that there is no semantic system that could incorporate all the truth about everything, and that the best we can do in order to keep a synoptic vision is (methodologically) trying to find connections between different stories, and not (ontologically) trying to summarize them in a greater one. Brandom, of course, insists that Kant discovered, and Sellars re-discovered, that factuality relies on modality and activity on normativity, but is not interested at all in deducing from this crucial point something about the essence of human beings or nature. In doing this - in saying, following David Lewis, that what matters is knowing and not believing - he is probably abandoning Sellars's definition of philosophy as something that tries to find the universal connection through all the things.

This comparison between Sellars's two most influential scholars has been necessary in order to show something that generally comes up only from the study of the (untouched by Olen, coherently with the purposes of his book) consequences of a system of thought: its precious incoherence. The two fundamental aims in Sellars's philosophy seem to be, using a philosophia perennis language, an ambition to ordered totality and a claim for freedom from monistic exigencies. It is very probable that they are incompatible. In Olen's more historically contextualized words "Sellars's reliance on such facts [that including normativity in philosophy of language would imply abandon formalism], though not exhausting his conception of normativity, is largely responsible for the tension between normative and naturalistic commitments in Sellars's philosophy" (3). Often, when Sellars found a sharp opposition like this one, he tried to solve it accepting a weakened version of the first side and refusing the second, but preserving something of its empirical aspect; he did so in the famous opposition between the scientific and the manifest image of man, accepting the metaphysical aims of the former and the empirical exigencies of the latter, and he did the same also about that "tension" answering it with his peculiar nominalism. Since the ancient problem of universals had three solutions (realism, conceptualism and nominalism), and Sellars judged improbable the metaphysics of the first and even more suspicious the mentalist ontology of the second, he was with no doubt a nominalist, however his own antidichotomic way. 
10 The general idea is that, if a proper semantics has to get an explanatory role, it only needs seeming to contain universals. These universals will be categories of behavior, and so they will be at the same time epistemological tools and references to the empirical world. As far as we can understand from Olen's reconstruction, lastly, Sellars ended up in giving the role of the rationalistic exhaustiveness to the uniformity of human behaviors, and the role of empirical contingency to the arbitrary constitution of natural languages.

11 As it is well known, between their death and their becoming a classic all the important philosophers live four or five decades of dereliction, when their works are at best only quoted and their original purposes deformed (often with an improvement, without doubt) by their scholars. Peter Olen's Wilfrid Sellars and the Foundations of Normativity is, together with other increasingly numerous studies, a crucial step in order to bring Sellars out from that state and make of him a true classic. We can also say that the goal explicitly pursued by the author has been successfully met: the reader gets a vivid picture of Sellars's philosophical backgrounds, continuities - somehow, Olen's attention on individuating two phases of Sellars's thought makes us better understand the continuity between them - and discontinuities, following the natural development of his thought without the teleologism that often afflicts systematic reconstructions. Since the criterion of exposition is mostly chronological, sometimes we have to put different elements about the same topic together from distinct sections of the book in order to find the theoretical connection. As a matter of fact, although the topics should be pure pragmatics and normativity, we find all the crucial elements of Sellars's philosophy, as nominalism, epistemological behaviorism, and the interaction between empirical sciences and philosophy. But, perhaps, such an irregularity is more capable to give us the original proceeding of Sellars's thought than any philological explanation would have been. Lastly, the Appendix of unpublished texts and documents gives us a rich and unusual view on the cultural environment where the last aims of traditional pragmatism and neo-positivism melted into the analytic philosophy, making us understanding - from the pen of some of its protagonists - the genesis of many of latter's peculiarities.

\section{AUTHORS}

\section{GABRIELE ALEANDRI}

Università degli Studi Roma Tre

G.92.A[at]hotmail.com 